\title{
Clinical features and gene mutational spectrum of CDKL5-related diseases in a cohort of Chinese patients
}

Ying Zhao ${ }^{1+}$, Xiaoying Zhang ${ }^{1 \dagger}$, Xinhua Bao ${ }^{1 *}$, Qingping Zhang ${ }^{1}$, Jingjing Zhang ${ }^{1}$, Guangna Cao ${ }^{1}$, Jie Zhang ${ }^{2}$, Jiarui $\mathrm{Li}^{2}$, Liping Wei ${ }^{2}$, Hong Pan ${ }^{1}$ and Xiru Wu${ }^{1}$

\begin{abstract}
Background: Mutations in the cyclin-dependent kinase-like 5 (CDKL5) (NM_003159.2) gene have been associated with early-onset epileptic encephalopathies or Hanefeld variants of RTT(Rett syndrome). In order to clarify the CDKL5 genotype-phenotype correlations in Chinese patients, CDKL5 mutational screening in cases with early-onset epileptic encephalopathies and RTT without MECP2 mutation were performed.

Methods: The detailed clinical information including clinical manifestation, electroencephalogram (EEG), magnetic resonance imaging (MRI), blood, urine amino acid and organic acid screening of 102 Chinese patients with early-onset epileptic encephalopathies and RTT were collected. CDKL5 gene mutations were analyzed by PCR, direct sequencing and multiplex ligation-dependent probe amplification (MLPA). The patterns of X-chromosome inactivation (XCI) were studied in the female patients with CDKL5 gene mutation.
\end{abstract}

Results: De novo CDKL5 gene mutations were found in ten patients including one missense mutation (c.533G > A, p. R178Q) which had been reported, two splicing mutations (ISV6 + IA $>$ G, ISV13 + IA > G), three micro-deletions (c.1111delC, c.2360delA, c.234delA), two insertions (c.1791 ins G, c.891_892 ins TT in a pair of twins) and one nonsense mutation (c.1375C > T, p.Q459X). Out of ten patients, 7 of 9 females with Hanefeld variants of RTT and the remaining 2 females with early onset epileptic encephalopathy, were detected while only one male with infantile spasms was detected. The common features of all female patients with CDKL5 gene mutations included refractory seizures starting before 4 months of age, severe psychomotor retardation, Rett-like features such as hand stereotypies, deceleration of head growth after birth and poor prognosis. In contrast, the only one male patient with CDKL5 mutation showed no obvious Rett-like features as females in our cohort. The X-chromosome inactivation patterns of all the female patients were random.

Conclusions: Mutations in CDKL5 gene are responsible for 7 with Hanefeld variants of RTT and 2 with early-onset epileptic encephalopathy in 71 girls as well as for 1 infantile spasms in 31 males. There are some differences in the phenotypes among genders with CDKL5 gene mutations and CDKL5 gene mutation analysis should be considered in both genders.

Keywords: CDKL5 mutations, Early-onset epileptic encephalopathy, X chromosome inactivation

\footnotetext{
*Correspondence: zwhang@pku.edu.cn

'Equal contributors

${ }^{1}$ Department of Pediatrics, Peking University First Hospital, Beijing 100034

China

Full list of author information is available at the end of the article
}

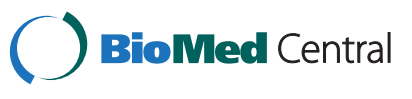

(c) 2014 Zhao et al.; licensee BioMed Central Ltd. This is an Open Access article distributed under the terms of the Creative Commons Attribution License (http://creativecommons.org/licenses/by/2.0), which permits unrestricted use, distribution, and reproduction in any medium, provided the original work is properly credited. The Creative Commons Public Domain Dedication waiver (http://creativecommons.org/publicdomain/zero/1.0/) applies to the data made available in this article, unless otherwise stated. 


\section{Background}

Mutations in the cyclin-dependent kinase-like 5 gene (CDKL5, OMIM 300203) have been described in CDKL5related disorders including early-onset seizure variant of rett syndrome and early-onset epileptic encephalopathies [1]. Although CDKL5 mutation screenings are generally performed in cohorts of Rett syndrome (RTT) or a variant of it, individuals with CDKL5 mutation present their unique characteristics. Intractable epilepsy that resistant to multiple antiepileptic drugs (AEDs) often starts within 6 months of age and is associated with severe mental retardation without obvious period of regression. Clinical manifestations of subsequent cases with CDKL5 mutation closely resemble some features of RTT including hand stereotypies, autistic-like features, scarce acqusition of language and concious hand use. Accumulated evidence show that phenotype of CDKL5-related disorders overlaps with early-onset seizure variant of RTT (RTT, OMIM 312750) and early-onset epileptic encephalopathies with Xlinked infantile spasms (ISSX,OMIM308350) [2-7]. Nowadays, the phenotypic spectrum range of CDKL5-related diseases has expanded. More than 80 mutations in CDKL5 had been reported, in which $10 \%$ females were found with early-onset seizure variant of RTT, early infantile epileptic encephalopathy-2 and myoclonic encephalopathy [8-10]. Different CDKL5 mutation types include missense mutations, nonsense mutations, splicing mutations and deletion/ insertions causing frameshifts and premature truncation [11]. Large rearrangement of the CDKL5 gene has been detected by multiple ligation-dependent probe amplification (MLPA) [7,10,12]. The reported mutations locate almostly across all exons of CDKL5 gene and disrupt either the catalytic domain or the C-terminus domain of CDKL5 protein. Recent data suggests that missense mutations located in the catalytic domain of CDKL5 could exhibit more severe clinical manifestation than that caused by truncated mutations located in the C-Terminal of CDKL5 [13]. However, further investigation is still needed to elucidate the relationship between clinical severity and mutation types and locations. Although most of the CDKL5 mutations are found in females, they also present in some males. Recognition of male CDKL5 mutation carriers broadens the spectrum of $C D K L 5$-related diseases and suggests that CDKL5 mutation screening should be carried out in both genders [14].

The purpose of this study is to delineate the clinical manifestation of Chinese patients with CDKL5-related diseases, identify the CDKL5 genotype-phenotype correlation in both genders and broaden the spectrum of CDKL5 mutations. Although information of Japanese Asian and Indian Asian have been published [14,15], the similar data are scarce in Chinese Asian. This work is the first study of CDKL5-related diseases in a large cohort of Chinese patients.

\section{Methods}

\section{Patients}

One hundred and two Chinese patients, including 71 females and 31 males, were recruited after informed consent obtained from the parents of the patients. The median age was 1 year and 4 months (ranged from 1 month to 12 years). Among them, 64 cases were diagnosed with early-onset epileptic encephalopathies, including 36 with infantile spasm, 8 with Ohtahara syndrome, and 20 with unknown epileptic syndrome. The seizures of the patients presented within six months of life without known causes in all cases recruited in our cohort. Thirty-eight cases were diagnosed with RTT, including 16 with classical RTT, 10 with congenital RTT, 3 with preserved speech variant RTT and 9 with Hanefeld variant of RTT. MECP2 mutations were negative in all the RTT patients. The clinical information was collected from family questionnaire as well as clinicians' reviews. Laboratory investigations included blood and urine amino acid and organic acid screening, brain MRI and electroencephalogram (EEG). Ethical approval was obtained from Clinical Research Ethics Committee, Peking University First Hospital.

\section{CDKL5 gene mutational analysis}

Genomic DNA was extracted from the peripheral blood leukocytes of the patients and their parents. CDKL5 gene (NM_003159.2) mutations were analyzed by polymerase chain reaction (PCR) and direct sequencing. PCR was carried out in $25 \mathrm{ul}$ reaction system with $2 \times$ GC Buffer I 12.5 ul, deionized $\mathrm{H}_{2} \mathrm{O} 4.5 \mathrm{ul}, 5^{\prime}$ primer 2 ul (5Pmol), 3' primer 2 ul (5Pmol), dNTPs 2 ul, platinum rTaq DNA polymerase (Invitrogen) $1 \mathrm{ul}$ and DNA template $1 \mathrm{ul}$. The annealing temperature was $59^{\circ} \mathrm{C}$ for exon1-21 except for exon 5 with $57^{\circ} \mathrm{C}$. Primer sequences and polymerase chain reaction conditions are available upon request. GenBank accession number NM_003159.2 was used as the DNA reference sequence. The nomenclature used follows the HGVS mutation nomenclature guidelines (www.hgvs.org). Pathogenicity prediction of previously unreported variants was performed using Alamut version2.0 (Interactive Biosoftware, Rouen, France). When no mutation was founded, MLPA (SALSA MLPA kit P189 CDKL5, MRC-Holland, Amsterdam, Holland) was performed to detect large deletions or duplications of CDKL5 gene, according to the previous reports $[16,17]$.

\section{The pattern of $\mathrm{XCl}$ in female patients with CDKL5 mutation}

The pattern of XCI was analyzed in the female patients with CDKL5 gene mutations, according to the procedures described by Allen et al. [18]. XCI was considered skewed if the ratio was $\geq 80: 20$, and considered extremely skewed if the ratio was $\geq 85: 15$. 


\section{Results}

\section{CDKL5 gene mutations}

De novo CDKL5 gene mutations were found in ten patients including one missense mutation (c.533G > A, p.R178Q) which had been reported, two splicing mutations (ISV6 + $1 \mathrm{~A}>\mathrm{G}$, ISV13 + 1A > G), three micro-deletion (c.1111delC, c.2360delA, c.234delA), two insertions (c.1791 ins G, c.891_892 ins TT in a pair of twins) and one nonsense mutation (c.1375C > T, p.Q459X). Among the ten patients, nine were females $(12.6 \%, 9 / 71)$ and one was male $(3.22 \%$, $1 / 31)$. The mutation rate was $9.8 \%(10 / 102)$. Out of the patients who carried a mutation, one male $(2.77 \%, 1 / 36)$ case was diagnosed with infantile spasm, followed by seven female $(77.7 \%, 7 / 9)$ with the Hanefeld variant of RTT, two female $(10 \%, 2 / 20)$ with unknown epileptic syndrome and none $(0 \%, 0 / 8)$ with Ohtahara syndrome. No mutation was found in their parents (Table 1).

\section{$\mathrm{XCl}$ pattern}

All the nine female patients with CDKL5 gene mutations had random $\mathrm{X}$ chromosome inactivation. The ratios were $50: 50,63: 37,55: 45,53: 47,58: 42,60: 40,56: 44,52: 48$ and 54:46, respectively (shown in Table 1 ).

\section{Clinical manifestation}

Among the ten patients with CDKL5 gene mutation in the cohort, phenotype consisted of 7 females with Hanefeld variant of RTT, 1 male with infantile spasms and 2 females with early onset epileptic encephalopathy at the first referral. All the ten patients were attacked by early onset seizures before 4 months of age (from 10 days to 100 days after birth). Various seizure types presented in the course of the disease including epileptic spasms, partial seizure, myoclonic seizure and tonic seizure. However, all the patients were initially attacked by partial seizure, and then it transformed to spasm or to the case that including both partial seizure and spasm after a period of time (10 days to 2.4 years). In the follow-up evaluation, myoclonic seizure and tonic seizure presented together with the original seizure types in two patients. All types of seizure in the patients with CDKL5 gene mutation were intractable and resistant to the antiepileptic drugs (AEDs). Hypsarrhythmia was identified on EEG records in five patients. Some Rett-like features presented in 9 female patients, such as the presence of hand-mouthing, hand washing or clapping became apparent in the first year of life in all of the female patients. All the patients with CDKL5 mutation showed severe psychmotor developmental delay. In addition, hypotonia, poor to absent acquisition of language, limited hand skills, poor eye contact, autonomic dysfunction features and autistic symptoms were the common features in all the patients. MRI, blood and urine amino acid and organic acid were normal in all the patients. Detailed information may be found online in the supporting information part (Additional file 1).

\section{Discussion}

Kalscheuer reported two unrelated girls with infantile spasms and mental retardation whose CDKL5 gene were disrupted by different balanced X-autosome translocations in 2003 [19]. Since then, only about 80 cases with CDKL5 mutations have been reported around the world. The patients have various phenotypes including early-onset seizure variant of RTT, X-linked infantile spasms, early infantile epileptic encephalopathy-2, autism spectrum disorders (ASDs) and Rett-like syndrome or Angleman-like syndrome [20-24].

In this paper, we submit a report on ten more cases of CDKL5-related diseases, which is the first report on Chinese asian. Nine females and one male with CDKL5 gene mutations are found in 102 patients with earlyonset epileptic encephalopathy and RTT. The overall mutation rate of CDKL5 is $9.8 \%(10 / 102)$, which is similar to that of previous studies $[6,9,14]$. Among the patients with CDKL5 gene mutations, 2 are diagnosed with early onset epileptic encephalopathy, 1 with infantile spasms and 7 with early-onset seizure of RTT syndrome when they were first referred to the clinician. It is worth noting that the two females with early onset epileptic encephalopathy present many characteristics of early-onset seizure of RTT syndrome in the follow-up assessment. The CDKL5 gene mutations in our patients include missense mutation $(1 / 10)$, nonsense mutation $(1 / 10)$, splicing mutations (2/10) and insertion/deletion mutation (6/10) causing frameshifts. No large rearrangement of the CDKL5 gene is found. All the mutations are proved to be de novo, and no mutations are further detected in their parents. Among the detected mutations in this paper, p.R178Q carried by a boy and a splicing mutation IVS6 + 1G > A carried by a girl are reported previously $[3,4,16,21]$.

Epilepsy is the core symptom of the patients with CDKL5 mutation. Bahi-Buisson $\mathrm{N}$ [13] concluded three successive stages of the epilepsy: early epilepsy (onset 110 weeks) with normal interictal EEG (stage I); epileptic encephalopathy with infantile spasms and hypsarrhythmia (stage II); refractory tonic seizures and myoclonia (stage III). In all our patients, the clinical manifestations are seizures, occurring in a range from 10 days to 100 days, the average of which is 47 days. The initial seizure type of all the patients is partial seizure. Epileptic spasm presents in 9 patients several days to 2 years after the onset of partial seizure. Other seizure types including myoclonic seizure, tonic seizure and atypical absence presents in two patients. Hypsarrhythmia or atypical hypsarrhythmia are found in five patients. The epileptic events are resistant to all treatments including the antiepileptic drugs, ACTH and ketogenic diet. In all our patients, frequent seizure continues 
Table 1 Detailed clinical manifestations, mutations and ration of $\mathrm{XCl}$ of patients

\begin{tabular}{|c|c|c|c|c|c|c|c|c|c|}
\hline NO. & Patient 1 & Patient 2 & Patient 3 & Patient 4 & Patient 5 & Patient 6 and 7 & Patient 8 & Patient 9 & Patient 10 \\
\hline Age & $2 \mathrm{yrs}$ & 3 yrs & 3 yrs & 4 yrs & $5 \mathrm{yrs}$ & $2 \mathrm{yrs}$ and $6 \mathrm{mo}$ & $5 \mathrm{mo}$ & $13 \mathrm{mo}$ & $2 \mathrm{yrs}$ and $9 \mathrm{mo}$ \\
\hline Gender & $\mathrm{F}$ & $\mathrm{F}$ & $\mathrm{F}$ & $\mathrm{F}$ & $\mathrm{F}$ & $\mathrm{F}$ & M & $\mathrm{F}$ & $\mathrm{F}$ \\
\hline Seizure onset & $22 \mathrm{ds}$ & $10 \mathrm{ds}$ & $1.2 \mathrm{mo}$ & $3.3 \mathrm{mo}$ & $1 \mathrm{mo}$ & $2.3 \mathrm{mo}$ & $2 \mathrm{mo}$ & $1.2 \mathrm{mo}$ & $1.3 \mathrm{mo}$ \\
\hline Partial seizures & 22 ds- now & $10 \mathrm{ds}-2 \mathrm{yrs}$ & 1.2 mo- now & $3.3 \mathrm{mo}-3 \mathrm{yrs}$ & 1 mo-now & 2.3 mo-now & 2 mo-now & 1.2 mo-now & 1.3 mo-now \\
\hline Spasm & 2.2 mo-now & 2 mo-now & 1.5 mo-now & $3.7 \mathrm{mo}-3 \mathrm{yrs}$ & 1.5 yrs-now & 3 mo-now & 2 mo-now & - & 2.5 yrs-now \\
\hline Myoclonic seizures & - & 2 yrs-now & - & - & - & - & - & - & 2.8 yrs-now \\
\hline Tonic seizures & - & 2 yrs-now & - & - & - & - & - & - & 2.8 yrs-now \\
\hline Drug resistance & + & + & + & + & + & + & + & + & + \\
\hline Hypsarrhythmia & - & + & - & - & + & + & + & - & - \\
\hline Deceleration of head growth & + & + & + & + & + & + & + & + & + \\
\hline Hypotonia & + & + & + & + & + & + & + & + & + \\
\hline Limited hand skills & + & + & + & + & + & + & + & + & + \\
\hline Stereotypies & + & + & + & + & + & + & - & + & + \\
\hline Sit unaided & $16 \mathrm{mo}$ & $11 \mathrm{mo}$ & $18 \mathrm{mo}$ & $24 \mathrm{mo}$ & $6 \mathrm{mo}$ & $6 \mathrm{mo}$ & - & - & - \\
\hline Walk (ever) & - & - & - & - & A few steps & - & - & - & - \\
\hline Speech & Absent & One word & Absent & Absent & Absent & Absent & Absent & Absent & Absent \\
\hline Autistic features ${ }^{\mathbf{a}}$ & + & + & + & + & + & + & + & + & + \\
\hline Autonomic features $^{\mathbf{b}}$ & NA & + & NA & + & + & + & - & + & + \\
\hline MRI or $C T$ & - & - & - & - & - & - & - & - & - \\
\hline CDKL5 mutations & c.1111 delC & $\mathrm{ISV} 13+\mathrm{A}>\mathrm{G}$ & c.1791 insG & $1 S V 6+1 A>G$ & c. $1375 C>T_{i}$ & c.891_892ins TT & c.533G > A & c.2360delA & c.234delA \\
\hline Position of mutatins & C-terminal & C-terminal & C-terminal & Catalytic domain & C-terminal & Catalytic domain & Catalytic domain & C-terminal & Catalytic domain \\
\hline $\mathrm{XCl}$ ratio & $50: 50$ & $63: 37$ & $55: 45$ & $53: 47$ & $58: 42$ & $60: 40 / 56: 44$ & - & $52: 48$ & $54: 46$ \\
\hline
\end{tabular}

Abbreviations: EOEE, early onset epileptic encephalopathy; Hanefeld RT, Hanefeld variant of Rett syndrome; IS, infantile spasms; F, female; M, male; yrs, years; mo, months; ws, weeks; ds, days; HC, head circumference; $\mathrm{cm}$, centimeter; NA, nonavailable.

a autistic features include avoidance of eye gazing, reduced social interaction.

bautonomic features include breathing dysrhythmia, hypalgesic, bruxism, cold extremities. 
even after the extensive treatment except for case 4 who was seizure-free 3-years later.

All the patients show severe psychmotor developmental delay. Seven patients could sit unaided, the time delayed in 6 patients is in the range from 8 months to 24 months, the average which is 12.5 months. The other three cases aged from 5 months to 2 years and 9 months could not sit at all. Nine patients could not walk. All the female patients with CDKL5 mutation show some Rett-like features such as stereotypic hand movements. The presence of handmouthing, hand washing or clapping becomes apparent in the first year of life in seven patients. In addition, hypotonia, limited hand skills, poor eye contact and autistic symptoms are the common features of all the patients. Although the symptoms of our patients with CDKL5 mutations overlap with some features of Hanefeld variant of RTT, recent reports have clarified that CDKL5-related disorder should be considered as separate from RTT, rather than another variant $[25,26]$.

Despite the common features shared by patients with CDKL5 mutation of both genders, there are some phenotypic differences between females and males $[3,16]$. Seven males with CDKL5 mutations have been reported so far, which are much less than females. Bahi-Buisson $\mathrm{N}$ conducted a comparison of clinical features between both genders. The results showed that none of the reported males acquired language skills ( $0 \%$ vs $12.3 \%)$ or ambulation with or without aid ( $0 \%$ vs $32.4 \%$ ) compared to female patients. Of greater interest is that Rett-like features such as hand stereotypies have scarcely been reported in males with $C D K L 5$ mutations [3,16,27-29]. In agreement with the reported male characteristics, the male patient aged 5 months in our cohort manifests early-onset seizures, hypotonia, poor eye contact and poor response to antiepileptic drugs. He does not acquire hand skills and never develop apparent hand stereotypies as female patients. The clinical manifestations still need further observations due to the young age of the boy. The most recent reports indicates that there are no differences in clinical severity between both genders with CDKL5 mutation [8], and more male cases are necessary to support this conclusion.

CDKL5 encodes a serine threonine kinase protein composed of a catalytic domain and a long C-terminal extension. Catalytic domain regulates the catalytic activity of CDKL5 gene and the C-terminal involves in sub-nuclear localization of the protein and negatively regulates the catalytic activity [30]. The clinical severity may be associated with the location and the type of mutations, but the genotype-phenotype correlation still remains obscure [22]. It has been reported that some recurrent mutations in $\mathrm{N}$ terminal catalytic domain such as p.Arg59X, p.Arg134X, p.Arg178Trp/Pro/Gln, c.145 + $2 \mathrm{~T}>\mathrm{C}$ and frameshift mutations in the C-terminal region such as c.2635_2636del CT cause more severe phenotype, which is manifested by earlier onset, infantile spasms and hypsarrhythmia, refractory epileptic encephalopathy, microcephaly, and inability to walk [31]. The patients with p.Ala40Val mutation which affects ATP-binding site in catalytic domain, showed mild phenotype (walked unaided, normocephaly, better hand use ability, and less frequent refractory epilepsy), compared to those with other CDKL5 mutations $[5,6,13]$. Russo et al. proposed that patients with stop codon mutations have a milder phenotype than those with missense or splicing mutations [12]. In our cohort, there are no obvious differences between catalytic domain (patient 4, 6 and 7, 8 and 10) and C-terminal (patient 1, 2, 3, 5 and 9) domain. Patient 4 with splicing mutation shows seizurefree after 3-year old. She is the only patient who could walk a few steps and sit unaided at 6 months. Therefore, in our study we cannot develop any clear relationship between the clinical manifestation and the type of CDKL5 mutations, due to the limited number of mutation samples in our study. The pattern of XCI is known as the important modulator of the phenotype in X-link genetic diseases. Kalscheuer VM et al. [19] found that the normal X chromosome in two females with heterozygous CDKL5 mutations was functionally absent, suggesting CDKL5 located in $\mathrm{X}$ gene was subject to inactivation in female somatic cells. Tao et al. [20] showed that variable expression of the wild-type CDKL5 allele was associated with intrafamilial phenotypic variability of the disease. However, both Weaving et al. [21] and Evans JC et al. [3] reported that twin sisters with the similar XCI pattern in cells from peripheral blood exhibited completely different clinical features. Hence, different phenotypes do not appear to be as a result of X-inactivation status. In this study, all the 9 females with CDKL5 mutations have random XCI patterns and we may conclude that the differences of their clinical manifestations could not be attributed to XCI. Similar results are reported in the references [6,9]. It is worth noting that the XCI pattern in peripheral blood may not necessarily reflect the XCI pattern in neurons. Furthermore, the distribution of XCI in brain may differ from region to region due to its tissue-specific variation [32]. Therefore, in order to develop an effective relationship between the pattern of XCI and clinical manifestations, the above questions should be addressed first in future.

\section{Conclusions}

This study is the first report of Chinese patients with CDKL5 gene mutations. The common clinical features of the ten patients with CDKL5 mutations include none or limited language development, severe hypotonia, deceleration of head growth, hand apraxia and hand stereotypies, as well as early-onset seizures presented initially as partial seizures and soon transformed to spasms. CDKL5 mutation is an important cause in female patients with early onset epilepsy and severe psychomotor retardation without 
known etiology. In our study we cannot develop any clear relationship between the clinical manifestation and the type of CDKL5 mutations as well as the XCI pattern. Complete screening of CDKL5 exons including MLPA tests should be performed on both genders, although large rearrangement had not been detected in our cohort.

\section{Additional file}

Additional file 1: Online supplement detailed clinical manifestations of the patients with CDKL5 mutation in our cohort.

\section{Competing interests}

The authors declare no conflict of interests.

\section{Authors' contributions}

XB obtained the funding and design the research. YZ, XZ, QZ, JZ, GC, JZ and $\mathrm{J}$ acquired and provided clinical data and samples from patients. $Y Z$ and $X Z$ carry out the laboratory work, QZ, JZ, GC, JZ and JL helped preparing the laboratory work. $Y Z$ analyzed most of the data and draft the manuscript. XB, LW, HP, XW revised the manuscript. All authors read and approved the final manuscript.

\section{Acknowledgments}

This project was financially supported by Grants of Capital Clinical Characteristic Application Research (Z121107001012049) from Beijing Science \& Technology Committee, Peking University 985 Clinical Hospital Cooperation Project and National Natural Science Foundation of China (H81070911). We are very grateful to Dr. Alan Percy (University of Alabama, Civitan International Research Center) for revising the manuscript.

\section{Author details}

${ }^{1}$ Department of Pediatrics, Peking University First Hospital, Beijing 100034, China. ${ }^{2}$ National Institute of Biological Sciences, Peking University, Beijing 100871, China.

Received: 17 October 2013 Accepted: 12 February 2014 Published: 25 February 2014

\section{References}

1. Artuso R, Mencarelli MA, Polli R, Sartori S, Ariani F, Pollazzon M, Marozza A, Cilio MR, Specchio N, Vigevano F, Vecchi M, Boniver C, Dalla Bernardina B, Parmeggiani A, Buoni S, Hayek G, Mari F, Renieri A, Murgia A: Early-onset seizure variant of Rett syndrome: definition of the clinical diagnostic criteria. Brain Dev 2010, 32(1):17-24.

2. Scala E, Ariani F, Mari F, Caselli R, Pescucci C, Longo I, Meloni I, Giachino D, Bruttini M, Hayek G, Zappella M, Renieri A: CDKL5/STK9 is mutated in Rett syndrome variant with infantile spasms. J Med Genet 2005, 42(2):103-107.

3. Evans JC, Archer HL, Colley JP, Ravn K, Nielsen JB, Kerr A, Williams E, Christodoulou J, Gecz J, Jardine PE, Wright MJ, Pilz DT, Lazarou L, Cooper DN, Sampson JR, Butler R, Whatley SD, Clarke AJ: Early onset seizures and Rett-like features associated with mutations in CDKL5. Eur J Hum Genet 2005, 13(10):1113-1120.

4. Archer HL, Evans J, Edwards S, Colley J, Newbury-Ecob R, O'Callaghan F, Huyton M, O'Regan M, Tolmie J, Sampson J, Clarke A, Osborne J: CDKL5 mutations cause infantile spasms, early onset seizures, and severe mental retardation in female patients. J Med Genet 2006, 43(9):729-734.

5. Rosas-Vargas H, Bahi-Buisson N, Philippe C, Nectoux J, Girard B, N'Guyen Morel MA, Gitiaux C, Lazaro L, Odent S, Jonveaux P, Chelly J, Bienvenu T: Impairment of CDKL5 nuclear localisation as a cause for severe infantile encephalopathy. J Med Genet 2008, 45(3):172-178.

6. Nemos C, Lambert L, Giuliano F, Doray B, Roubertie A, Goldenberg A, Delobel B, Layet V, N'Guyen MA, Saunier A, Verneau F, Jonveaux P, Philippe C: Mutational spectrum of CDKL5 in early-onset encephalopathies: a study of a large collection of French patients and review of the literature. Clin Genet 2009, 76(4):357-371

7. Maortua H, Martinez-Bouzas C, Calvo MT, Domingo MR, Ramos F, Garcia-Ribes A, Martinez MJ, Lopez-Ariztegui MA, Puente N, Rubio I, Tejada MI: CDKL5 gene status in female patients with epilepsy and Rett-like features: two new mutations in the catalytic domain. BMC Med Genet 2012, 13:68.

8. Bahi-Buisson N, Bienvenu T: CDKL5-related disorders: from clinical description to molecular genetics. Mol Syndromol 2012, 2(3-5):137-152.

9. Bahi-Buisson N, Nectoux J, Rosas-Vargas H, Milh M, Boddaert N, Girard B, Cances C, Ville D, Afenjar A, Rio M, Héron D, N'guyen Morel MA, Arzimanoglou A, Philippe C, Jonveaux P, Chelly J, Bienvenu T: Key clinical features to identify girls with CDKL5 mutations. Brain 2008, 131(Pt 10):2647-2661.

10. Buoni S, Zannolli R, Colamaria V, Macucci F, di Bartolo RM, Corbini L, Orsi A, Zappella M, Hayek J: Myoclonic encephalopathy in the CDKL5 gene mutation. Clin Neurophysiol 2006, 117(1):223-227.

11. Rademacher N, Hambrock M, Fischer U, Moser B, Ceulemans B, Lieb W, Boor R, Stefanova I, Gillessen-Kaesbach G, Runge C, Korenke GC, Spranger S, Laccone F, Tzschach A, Kalscheuer VM: Identification of a novel CDKL5 exon and pathogenic mutations in patients with severe mental retardation, early-onset seizures and Rett-like features. Neurogenetics 2011, 12(2):165-167.

12. Russo S, Marchi M, Cogliati F, Bonati MT, Pintaudi M, Veneselli E, Saletti V, Balestrini M, Ben-Zeev B, Larizza L: Novel mutations in the CDKL5 gene, predicted effects and associated phenotypes. Neurogenetics 2009, 10(3):241-250.

13. Bahi-Buisson N, Kaminska A, Boddaert N, Rio M, Afenjar A, Gerard M, Giuliano F, Motte J, Heron D, Morel MA, Plouin P, Richelme C, des Portes V, Dulac O, Philippe C, Chiron C, Nabbout R, Bienvenu T: The three stages of epilepsy in patients with CDKL5 mutations. Epilepsia 2008, 49(6):1027-1037.

14. Liang JS, Shimojima K, Takayama R, Natsume J, Shichiji M, Hirasawa K, Imai K, Okanishi T, Mizuno S, Okumura A, Sugawara M, Ito T, Ikeda H, Takahashi Y, Oguni H, Imai K, Osawa M, Yamamoto T: CDKL5 alterations lead to early epileptic encephalopathy in both genders. Epilepsia 2011, 52(10):1835-1842.

15. Das DK, Mehta B, Menon SR, Raha S, Udani V: Novel mutations in cyclindependent kinase-like 5 (CDKL5) gene in Indian cases of Rett syndrome. Neuromolecular Med 2013, 15(1):218-225.

16. Elia M, Falco M, Ferri R, Spalletta A, Bottitta M, Calabrese G, Carotenuto M, Musumeci SA, Lo Giudice M, Fichera M: CDKL5 mutations in boys with severe encephalopathy and early-onset intractable epilepsy. Neurology 2008, 71(13):997-999.

17. Neul JL, Kaufmann WE, Glaze DG, Christodoulou J, Clarke AJ, Bahi-Buisson N, Leonard H, Bailey ME, Schanen NC, Zappella M, Renieri A, Huppke P, Percy AK, RettSearch Consortium: Rett syndrome: revised diagnostic criteria and nomenclature. Ann Neurol 2010, 68(6):944-950.

18. Allen RC, Zoghbi HY, Moseley AB, Rosenblatt HM, Belmont JW: Methylation of Hpall and Hhal sites near the polymorphic CAG repeat in the human androgen-receptor gene correlates with $\mathrm{X}$ chromosome inactivation. Am J Hum Genet 1992, 51(6):1229-1239.

19. Kalscheuer VM, Tao J, Donnelly A, Hollway G, Schwinger E, Kubart S, Menzel C, Hoeltzenbein M, Tommerup N, Eyre H, Harbord M, Haan E, Sutherland $\mathrm{GR}$, Ropers HH, Gécz J: Disruption of the serine/threonine kinase 9 gene causes severe $\mathrm{X}$-linked infantile spasms and mental retardation. Am J Hum Genet 2003, 72(6):1401-1411.

20. Tao J, Van Esch H, Hagedorn-Greiwe M, Hoffmann K, Moser B, Raynaud M, Sperner J, Fryns JP, Schwinger E, Gecz J, Ropers HH, Kalscheuer VM: Mutations in the X-linked cyclin-dependent kinase-like 5 (CDKL5/STK9) gene are associated with severe neurodevelopmental retardation. Am J Hum Genet 2004, 75(6):1149-1154.

21. Weaving LS, Christodoulou J, Williamson SL, Friend KL, McKenzie OL, Archer H, Evans J, Clarke A, Pelka GJ, Tam PP, Watson C, Lahooti H, Ellaway CJ, Bennetts B, Leonard H, Gécz J: Mutations of CDKL5 cause a severe neurodevelopmental disorder with infantile spasms and mental retardation. Am J Hum Genet 2004, 75(6):1079-1093.

22. Kilstrup-Nielsen C, Rusconi L, La Montanara P, Ciceri D, Bergo A, Bedogni F, Landsberger N: What we know and would like to know about CDKL5 and its involvement in epileptic encephalopathy. Neural Plast 2012, 2012:728267.

23. Willemsen MH, Rensen $J H$, de Valk HM VS-L, Hamel BC, Kleefstra T: Adult phenotypes in Angelman- and Rett-like syndromes. Mol Syndromol 2012, 2(3-5):217-234.

24. White R, Ho G, Schmidt S, Scheffer IE, Fischer A, Yendle SC, Bienvenu T, Nectoux J, Ellaway CJ, Darmanian A, Tong $X$, Cloosterman D, Bennetts B, Kalra V, Fullston T, Gecz J, Cox TC, Christodoulou J: Cyclin-dependent kinase-like 5 (CDKL5) mutation screening in Rett syndrome and related disorders. Twin Res Hum Genet 2010, 13(2):168-178.

25. Guerrini R, Parrini E: Epilepsy in Rett syndrome, and CDKL5- and FOXG1gene-related encephalopathies. Epilepsia 2012, 53(12):2067-2078. 
26. Fehr S, Wilson M, Downs J, Williams S, Murgia A, Sartori S, Vecchi M, Ho G, Polli R, Psoni S, Bao X, de Klerk N, Leonard H, Christodoulou J: The CDKL5 disorder is an independent clinical entity associated with early-onset encephalopathy. Eur J Hum Genet 2013, 21(3):266-273

27. Castren M, Gaily E, Tengstrom C, Lahdetie J, Archer H, Ala-Mello S: Epilepsy caused by CDKL5 mutations. Eur J Paediatr Neurol 2011, 15(1):65-69.

28. Sartori S, Di Rosa G, Polli R, Bettella E, Tricomi G, Tortorella G, Murgia A: A novel CDKL5 mutation in a 47, XXY boy with the early-onset seizure variant of Rett syndrome. Am J Med Genet A 2009, 149A(2):232-236.

29. Fichou Y, Bieth E, Bahi-Buisson N, Nectoux J, Girard B, Chelly J, Chaix Y, Bienvenu T: Re: CDKL5 mutations in boys with severe encephalopathy and early-onset intractable epilepsy. Neurology 2009, 73(1):77-78. author reply 78 .

30. Bertani I, Rusconi L, Bolognese F, Forlani G, Conca B, De Monte L, Badaracco G, Landsberger N, Kilstrup-Nielsen C: Functional consequences of mutations in CDKL5, an X-linked gene involved in infantile spasms and mental retardation. J Biol Chem 2006, 281(42):32048-32056.

31. Bahi-Buisson N, Villeneuve N, Caietta E, Jacquette A, Maurey H, Matthijs G, Van Esch H, Delahaye A, Moncla A, Milh M, Zufferey F, Diebold B, Bienvenu T: Recurrent mutations in the CDKL5 gene: genotype-phenotype relationships. Am J Med Genet A 2012, 158A(7):1612-1619.

32. Sharp $A$, Robinson $D$, Jacobs $P$ : Age- and tissue-specific variation of $X$ chromosome inactivation ratios in normal women. Hum Genet 2000, 107(4):343-349.

doi:10.1186/1471-2350-15-24

Cite this article as: Zhao et al: Clinical features and gene mutational spectrum of CDKL5-related diseases in a cohort of Chinese patients. BMC Medical Genetics 2014 15:24.

\section{Submit your next manuscript to BioMed Central and take full advantage of:}

- Convenient online submission

- Thorough peer review

- No space constraints or color figure charges

- Immediate publication on acceptance

- Inclusion in PubMed, CAS, Scopus and Google Scholar

- Research which is freely available for redistribution 